\author{
Александр Цой \\ Лодзинский университет (Лодзь, Польша)
}

\title{
ПЕРЕВОД КАК СПОСОБ ТОЛКОВАНИЯ ЗНАЧЕНИЙ СЛУЖЕБНОГО СЛОВА
}

Служебные слова, как известно, не обладают предметным содержанием, и основная их функция - выражение различных отношений между знаменательными словами. Кроме того, существуют сложности описания их грамматических, функциональных и структурных характеристик.

Bсе это обостряет проблему адекватного понимания служебных слов иноязычными пользователями. Словарная статья в учебном толковом словаре в целом, а также иллюстративный материал, предложенный для семантизации заголовочного слова в виде словосочетаний и предложений в ней для инофонов ${ }^{1}$, представляют абстракции лингвистических структур изучаемого языка. Для преодоления этих трудностей иноязычным учащимся необходимо соотнесение леммы словарной статьи словаря изучаемого языка со словом в родном языке. То есть им необходимо представить соответствующее слово из их родной языковой системы. Особенно это необходимо для учебного толкового словаря. Таким образом, простейшим способом толкования русского служебного слова является его перевод на иностранный язык.

Образцом применения перевода служебных слов на иностранные языки является Краткий толковый словарь русского языка ${ }^{2}$ под ред. В. В. Розановой. В этом одноязычном толковом словаре в некоторых словарных статьях в квадратных скобках, вслед за определением, даются переводы служебных слов на английский, французский, испанский и немецкий языки. Сама идея включения перевода в словарную статью одноязычного толкового словаря очень интересна, но нет уверенности в том, что перевод соответствует частеречной принадлежности служебного слова, нет уверенности и в его адекватности и, соответственно, в его пользе. Тем более, что каждое слово в каждом конкретном языке обладает своей самостоятельной простой или сложной

${ }^{1}$ Инофон - учащийся-иностранец, носитель иностранного языка и соответствующей языковой картины мира.

2 Городецкая И. Л., Поповцева Т. Н., Судоплатова М. Н., Фоменко Т. А. (1987), Краткий толковый словарь русского языка, под ред. В. В. Розановой, 5-е изд., Москва. 
смысловой структурой, независимо от того, каким количеством эквивалентов весь объем его значения реально передается в другом каком-либо языке (Берков 2004: 116-117).

Смысловые структуры слов различных языков совпадают лишь в редких случаях. Например, словарная статья на следующую лексическую единицу:

НАВСТРЕ'ЧУ, нареч. и предлог с дательным падежом. В направлении, противоположном движению того, кто (или что) приближается [towards; a' la rencontre de; al encuentro; entgegen]. Идти', бежа'ть навстре'чу. Ве'тер дул навстре'чу. Навстре'чу нам шёл челове'к (Городецкая и другие 1987: 102).

Переводом снабжены также некоторые словарные статьи на союзы и частицы:

ВПРО'ЧЕМ, союз. Присоединяет предложение (или часть предложения), которое ограничивает или дополняет предыдущую мысль [however, but; du reste, d'ailleurs; adema's; übrigens]. Фильм хоро́ший, впро́чем тьл сам уви́дишь (Городецкая и другие 1987: 32).

И'МЕННО, частица. Употр., чтобы подчеркнуть слово, выражение [just; pre'cise'ment; precisamente; gerade, nämlich]. И'менно здесь. И'менно сего'дня, а не за'втра. Я обращза'юсь и'менно к вам. Мне нужна' и'менно э'та кни'га (Городецкая и другие 1987: 72).

Рассмотренные словарные статьи демонстрируют сложность включения перевода в их текст, а антропоморфные цели требуют перевода, так как пользователь словаря нуждается в нем. При этом в словарных статьях на непроизводные служебные слова перевод не дается, хотя в этих случаях можно избежать ошибок и дать наиболее адекватные иноязычные параллели.

Как видим, это весьма сложная проблема. Относительно употребления в словаре перевода (как способа уточнения семантики служебного слова) существуют разные мнения.

С одной стороны, считается, что применение перевода в словарной статье в толковых словарях не пригодно для инонациональных пользователей. Причина несовершенства и неэффективности рассматриваемого способа раскрытия лексических значений связана с отсутствием полной семантической эквивалентности между словами разных языков (Алекторова 1981: 5-12).

С другой, существует положение о переводе как достаточно надежном способе семантизации русских слов (Беляев 1965; Берков 2004). Основным доводом в пользу применения перевода в словарях является фактор положительной транспозиции, то есть переноса умений и навыков родного языка на другой язык. Перевод усиливает антропоморфную функцию словаря, так как эквивалентные параллели из родного языка инофонов в толковых словарях облегчают и помогают усвоению русского языка, а также способствуют формированию осознанного билингвизма у них.

Считаем, что перевод не только передает информацию о значении служебного слова русского языка на родной язык учащихся, но и наглядно пред- 
ставляет различия в грамматическом оформлении, сочетаемости и объеме значений слова в русском и иностранном языках. Это важно для формирования у инонациональных учащихся «языкового чутья», для возможности прогнозирования специфических ошибок в русской речи, возникающих у них регулярно при изучении русских служебных слов.

Перевод обычно осуществляется, во-первых, подбором эквивалента в родном языке пользователя; во-вторых, переводом толкования; в-третьих, описательным толкованием на родном языке пользователей.

И хотя для толкового словаря русского языка вполне достаточным может быть подбор эквивалента в родном языке инофона, при разработке словарной статьи в целях улучшения ее качественных характеристик необходимо задействовать все возможные способы перевода, а в зависимости от сложности семантики служебного слова и его структуры, способы перевода целесообразно варьировать, выбирая тот, который наиболее точно отражает семантику кодифицируемого служебного слова.

Многокомпонентные по структуре и сложные по значению русские предлоги необходимо пояснять при помощи описательного толкования на втором языке; переводу нужно подвергать не только само слово, но и иллюстративный материал, содержащий словосочетания, предложения, речевые образцы; по возможности также должны быть переведены антонимы и синонимы предлогов.

Такие переводы русских служебных слов можно осуществлять только на основе строгого и всестороннего отбора иноязычных слов, используя наиболее адекватные соответствия, а для служебных слов - в основном нейтральные, стремясь к тому, чтобы перевод был нормативно правильным, кратким и удобным, и, насколько это возможно, соответствовал грамматической структуре и синтаксической функции русского слова. В переводе не должно быть ненормативных вариантов, а также следует избегать просторечной и малоупотребительной лексики.

Наиболее разработанными являются русско-английские, русско-французские, русско-испанские и другие двуязычные словари, в которых второй язык - европейский, и словари эти вызывают мало критических замечаний. Такая адекватность перевода связана с двумя главными факторами - объективным, поскольку языки (русский и другой европейский) обнаруживают определенную степень индоевропейской языковой близости, и субъективным, определяемым давней лексикографической традицией создания таких двуязычных словарей и потому существенными наработками в подобных словарных переводах. Так, наличие хороших двуязычных словарей, например, русско-английских, объясняется большим количеством в России высококвалифицированных специалистов в области английского языка: хорошие словари дают возможность овладеть иностранным языком на высоком профессиональном уровне (без словарей подобное изучение иностранного 
языка практически невозможно), а профессионально подготовленные лингвисты, блестяще владеющие этим иностранным языком, могут осуществить лексикографический проект самого высокого качества. Словарные статьи, как правило, выглядят следующим образом. Например, в русско-английском словаре:

без, безо предл. (рд.) without; (за вычетом) mi'nus; не интере'ca not without interest, of some i'nterest; $\sim$ исключе'ния without exce'ption; $\sim$ coмне'ния without/bey'ond doubt [...daut]; глу'постей! no no'nsense now!; одно'й мину'ты, двух, трёх (мину'т) час, два, три и m.д. one minute [-it], two, three (mi'nutes) to one, two, three, etc.; че'тверти час, два и m.д. a qua'rter to one, two, etc.; год $\sim$ трёх дней three days short of a year; $\sim$ вас (в ваше отсутствие) in your a'bsence; $\square$ и того' пло'хо it is bad eno'ugh as it is , или a'ny way [...i'naf...] (Туровер и другие 2000: 41).

Или, в Большом русско-испанском словаре Рубиниос (Rubiños) словарная статья на предлог около выглядит так:

О’КОЛО 1. нареч. (возле) cerca; никого' не' было ви'дно cerca no se veía a nadie; ходи'ть вокру'г да $\sim$ перен. andar con rodeos; 2. предлог + P. (возле) cerca de, al lado de; сядь меня' siéntate a mi vera; го'рода была' река' cerca de la ciudad había un río; 3. предлог + P. (приблизи'тельно) cerca de, alrededor de; килогра'мма cerca de un kilogramo; полу'ночи cerca de (alrededor de) la medianoche; сейча'с $\sim$ двух часо'в son cerca de las dos; я прие'ду $\sim$ шести' часо'в ве'чера llegaré a eso de (alrededor de) las seis de la tarde; что'-то того' (э'того) algo aproximadamente así (Туровер и другие 2000: 399).

Для большинства существующих двуязычных русско-инонациональных словарей характерна цельнооформленность, монолитность композиционного строения словарной статьи, которая отвлекает внимание пользователей, затрудняет поиск нужного значения служебного слова, не способствует запоминанию, как значения кодифицируемого слова, так и его правильного употребления.

В целях улучшения качественных характеристик антропоцентрической словарной статьи толкового словаря представляется целесообразным разделить ее на две части, первую «входную» часть - собственно русскую, и вторую - с «выходным» иностранным языком. Благодаря этому перевод кодифицируемого служебного слова предстает перед пользователем в более наглядном виде, разворачивая параллели. В левой стороне (входной язык) помещается русское служебное слово со всем набором лексикографического инвентаря. Правая сторона (выходной язык) словарной статьи, собственно, является инонациональной.

В качестве примеров приведем разработанные нами словарные статьи с английским и испанским переводами как с возможными языками-вариантами.

Словарная статья на предлог без в толковом учебном словаре может выглядеть следующим образом: 
БЕ3 (безо) - непроизводный предлог.

БЕ3 (безо) + Род. п.

I. Выражает объектные отношения.

1. При указании на отсутствие кого или чего-нибудь.

Без де'нег.

Чита'ть без очко'в.

2. Указывает на действие в отсутствие кого-нибудь.

Это случи'лось без вас.

Без тебя' ничего' не полу'чится.

я' без тебя' никто'.

3. Употребляется при словах

со значением количества.

Без пяти' шесть.

Он пришёл домо'й

без двадияати' мину'm час.
БE3 (безо) - Non-derivative preposition.

БE3 (безо) + possessive case

I. It expresses objective relations.

1. It indicates the

absence of someone or something.

Without money.

To read without glasses.

2. It points to the action in someone's absence.

It happened without you.

Without you nothing will happen.

I'm nothing without you.

3. It is used with the

expressions of quantity.

It is five minutes to six.

He came home twenty minutes

to one.

Словарная статья на предлог около в толковом словаре может быть представлена так:

О'КОЛО - производный (наречный)

предлог.

О'КОЛО + Род. п.

I. Выражает пространственные отношения. Указывает на субъект (объект), находящийся поблизости от кого-, чего-либо.

Стоя'ть о'коло до'ма.

Сядь о'коло меня'.

$[\neq]$ (антоним) - далеко' от, вдали' от.

[ ] (синоним) - вблизи', во'зле, ря'дом.

Сядь во'зле меня'.

$\mathrm{O}$ - о'коло (наречие).

Учени'к сиде'л о'коло, рассма'тривал рису'нки.

II. Выражает временные

отношения. Указывает

на приблизительное время

совершения действия.

Я отсу'тствовал на учёбе

о'коло неде'ли.

Прошло' о'коло трёх часо'в.

III. Выражает количественные

отношения. Указывает на

приблизительную меру

чего-нибудь.

Учёный прожи'л о'коло ста лет.

Я жил за грани'ией о'коло двух лет.
Derivative (adverbial)

preposition.

О'КОЛО + genitive case.

I. Expresses spatial relations when at the object (subject),

that is situated close to someone, something.

Stand near the house.

Sit near me.

$[\neq]$ (antonym) - far from.

$[\approx]$ (synonym) - close to, by, next to.

Sit next to me.

(homonym) - by, close by, quite near (adverb).

The pupil was sitting by,

watching the pictures.

II. Expresses time relations when

indicating on approximate time

of action.

$=$ about, there abouts.

I was absent from the lessons

for about a week.

About three hours passed.

III. Express quantitative relations

when indicating an approximate measure.

The scientist had lived for about one hundred years.

I have been living abroad for about two years. 
Для русско-испанского варианта нами была разработана словарная статья на предлог около в виде таблицы (Тsoi и другие 2006: 181-188).

\begin{tabular}{|c|c|}
\hline $\begin{array}{l}\text { О'КОЛО - производный (наречный) пред- } \\
\text { лог. }\end{array}$ & $\begin{array}{l}\text { Preposición derivada (tb. puede } \\
\text { realizar las funciones de adverbio). }\end{array}$ \\
\hline О'КОЛО + Род. п. & $\begin{array}{l}\text { О'КОЛО + Genitivo = Significado. } \\
\text { Equivalente en español a: cerca de, al lado de, } \\
\text { junto, alrededor de. }\end{array}$ \\
\hline $\begin{array}{l}\text { I. Выражает пространственные отношения. } \\
\text { Указывает на субъект (объект), находящийся } \\
\text { поблизости от кого-, чего-либо. }\end{array}$ & $\begin{array}{l}\text { I. Noción espacial: indica objeto situado cerca } \\
\text { de alguien/algo. } \\
\text { = Cerca de, al lado de. }\end{array}$ \\
\hline Стоя'ть о'коло до'ма. & Estar cerca de la casa. \\
\hline Сядь о'коло меня'. & Siéntate a mi lado. \\
\hline [₹] (антоним) - далеко' от, вдали' от. & {$[\neq]($ anto'nimos) - lejos de, alejado de. } \\
\hline [ح] (синоним) - вблизи', во'зле, ря'дом. & $\begin{array}{l}{[\approx](\text { sino'nimos }) \text { - al lado, en las cercanias, }} \\
\text { junto a. }\end{array}$ \\
\hline Сядь во'зле меня'. & Siéntate junto a mi. \\
\hline О - о'коло (наречие). & O (homónimo) - cerca (adverbio). \\
\hline $\begin{array}{l}\text { Учени'к сиде'л о'коло, рассма'тривал } \\
\text { рису'нки. }\end{array}$ & $\begin{array}{l}\text { El alumno estaba sentado cerca y miraba los } \\
\text { dibujos. }\end{array}$ \\
\hline $\begin{array}{l}\text { II. Выражает временные отношения. } \\
\text { Указывает на приблизительное время } \\
\text { совершения действия. }\end{array}$ & $\begin{array}{l}\text { II. Expresa nociones temporales. Indica } \\
\text { tiempo aproximado de la realizacio'n de la } \\
\text { accio'n: alrededor de, más o menos, unos/ } \\
\text { unas, aproximadamente. }\end{array}$ \\
\hline Я отсу'тствовал на учёбе о'коло неде'ли. & $\begin{array}{l}\text { Falte' a (la) clase aproximadamente (alrededor } \\
\text { de) una semana. }\end{array}$ \\
\hline Прошло' о'коло трёх часо'в. & Pasaron cerca de tres horas. \\
\hline $\begin{array}{l}\text { III. Выражает количественные отношения. } \\
\text { Указывает на приблизительную меру чего- } \\
\text { нибудь. }\end{array}$ & $\begin{array}{l}\text { III. Expresa relaciones cuantitativas. } \\
\text { Indica medida aproximada de algo. }\end{array}$ \\
\hline Учёный прожи'л о'коло ста лет. & El científico vivió cerca de 100 años. \\
\hline Я жсил за грани'цей о'коло двух лет. & $\begin{array}{l}\text { Estuve viviendo en el extranjero durante } \\
\text { aproximadamente (cerca de) dos años. }\end{array}$ \\
\hline
\end{tabular}

Левая «типовая» часть словарной статьи содержит полную информацию на русское служебное слово, а правая часть содержит необходимые пометы, толкования, примеры и прочее на иностранном языке.

Перевод, способствующий выявлению семантического сходства и различий двух языков в области служебных слов, несомненно, научит иноязычных пользователей прогнозировать ошибки в русской письменной и устной речи, а затем, исправлять их. 
Семантические представления, максимально описывающие функционирование служебного слова в контексте, являются основополагающими для антропоцентрического подхода в толковом словаре. Использование перевода в словарных статьях на служебные слова в толковых словарях позволит показать объективную картину их семантики и отразить все их связи и отношения в системе русского языка, повысит познавательные свойства толкового словаря.

\section{Библиография}

Алекторова Л. П. (1981), Принципы составления «Словаря русского языка для учашихся старших классов начиональных школ», [в:] Теоретические основы разработки словарей учебного типа: Сб. научн. тр., Москва, с. 5-12.

Ахманова О. С., Выгодская 3. С., Горбунова Г. П. и др. (2000), Большой русско-английский словарь, Москва.

Беляев Б. В. (1965), Очерки по психологии обучения иностранным языкам, Москва.

Берков В. П. (2004), Двуязычная лексикография, 2-е изд., перераб. и доп., Москва.

Городецкая И. Л., Поповцева Т. Н., Судоплатова М. Н., Фоменко Т. А. (1987), Краткий толковый словарь русского языка, под ред. В. В. Розановой, 5-е изд., Москва.

Туровер Г. Я., Ногейра Х., Рубиниос (Rubiños) (2000), Большой русско-испанский словарь, Москва.

Tsoi A., Gervilla E. Q., Gervilla A. Q. (2006), Способы перевода предлогов на испанский язык в учебном словаре русского языка, [в:] Mundo Eslavo. Revista de cultura y estudios eslavos. Granada: Universidad de Granada, No. 5, p. 181-188.

\section{TRANSLATION AS A WAY OF INTERPRETING THE MEANING OF A FUNCTION WORD}

(Summary)

It is necessary to divide the lemma in the academic explanatory dictionary into two parts in order to improve its quality. The Russian function word (source language) is introduced in the left with all lexicographic items.

The right side (target language) of the dictionary entry contains necessary interpretation, litters, examples in the fixed accordance with the source language entry

At the same time, the source Russian version will always be fixed, and the target language input can be filled in English, German, Spanish, French, Turkish or Polish translations respectively.

Keywords: academic explanatory dictionary, function words, translation. 


\section{ПЕРЕВОД КАК СПОСОБ ТОЛКОВАНИЯ ЗНАЧЕНИЙ СЛУЖЕБНОГО СЛОВА}

(Резюме)

Для улучшения качественных характеристик словарной статьи учебного толкового словаря представляется целесообразным разделить ее на две части. В левой стороне (входной язык) помещается русское служебное слово со всем набором лексикографического инвентаря. Правая сторона (выходной язык) словарной статьи, в строгом соответствии с левой, дает необходимое толкование, пометы, примеры и прочее на иностранном языке. При этом «русская» левая часть всегда будет стандартной, а «инонациональная» часть может наполняться, соответственно, английским, немецким, испанским, французским, турецким или польским переводами.

Ключевые слова: учебный толковый словарь, служебные слова, перевод. 